\title{
GESTAO PARTICIPATIVA DE RISCOS DE DESASTRES: O SISTEMA DE ALERTA E ALARME DE BASE COMUNITARIA DO CARDINÓT, NOVA FRIBURGO, RJ
}

\author{
Elisa Fracioli Ximenes ${ }^{(a)}$, Rita Montezuma ${ }^{(b)}$, Anderson Mululu Sato ${ }^{(c)}$ \\ (a) Doutoranda POSGEO/Universidade Federal Fluminense, elisaxim@ gmail.com \\ (b) Núcleo Interdisciplinar de Pesquisa de Paisagens Profa. Adjunta, POSGEO, Depto. de Geografia/Universidade \\ Federal Fluminense, ritamontezuma@id.uff.br \\ (c) Grupo de Pesquisa em Desastres Sócio-Naturais (GDEN), Departamento de Geografia e Políticas Públicas (DGP), \\ Instituto de Educação de Angra dos Reis (IEAR), Universidade Federal Fluminense (UFF), andersonsato @id.uff.br
}

\section{Eixo: GEOGRAFIA FÍSICA E DESASTRES NATURAIS}

\begin{abstract}
RESUMO
A gestão de riscos dos desastres socioambientais vem ganhando espaço nas agendas de regiões afetadas à medida que aumenta a frequência e danos humanos, ambientais e materiais dos eventos. No Brasil alguns setores vêm mobilizando esforços para criar normas institucionais para gestão do risco de desastres, contudo não têm sido incluídas as comunidades em risco. O modelo de gestão adotado na bacia hidrográfica do Córrego Dantas retrata uma gestão de riscos de desastres tecnocêntrica e militarizada. As sirenes do sistema de alerta e alarme implantadas pela Defesa Civil não mobilizam os moradores a saírem de suas casas. Especialistas atribuem esta não aderência à falta de inclusão da comunidade nas discussões e tomadas de decisão. Esta pesquisa visa contribuir para o fortalecimento da gestão participativa dos riscos de desastres na bacia do Córrego Dantas através do fortalecimento do Sistema de Alerta e Alarme de Base Comunitária existente no bairro do Cardinot.
\end{abstract}

Palavras chave: gestao de riscos, desastres, sistema de alerta e alarme, mapeamento participativo, Nova Friburgo

\section{Introdução}

Este artigo trata da Gestão Participativa dos Riscos de Desastres na Bacia do córrego Dantas, em Nova Friburgo, Rio de Janeiro, região profundamente afetada pela catástrofe ocorrida em janeiro de 2011. Debruça-se sobre o Sistema de Alerta e Alarme de Base Comunitária identificado no bairro do Cardinot, parte integrante da bacia, como base para o inicio da construção da gestão participativa dos riscos na região. O artigo faz parte da tese de doutorado em andamento no Programa de Pós Graduação do Curso de Geografia da Universidade Federal Fluminense, articula-se com as atividades da Rede de Gestão de Riscos de Desastres (REGER) da Bacia do Córrego Dantas (Freitas e Netto, 2016) e apresenta os resultados preliminares obtidos até a presente data.

Em 11 de janeiro de 2011, chuvas extremas acarretaram na maior catástrofe ocorrida na região Serrana do Rio de Janeiro e um dos maiores desastres socioambientais já ocorridos no ultimo século 
(Coelho Netto et al.,2015), levando sete municípios a decretar estado de calamidade pública. O número oficial de mortes foi superior a 900 pessoas além de 350 desaparecidas (Bertoni e Marinho, 2013), 8.795 desabrigados e 22.604 desalojados, resultando no impacto direto sobre a vida e saúde de mais de 32 mil habitantes, principalmente nos municípios de Petrópolis, Teresópolis e Nova Friburgo.

O rápido crescimento da população (entre 1950 e 2010 a população quadruplicou em Nova Friburgo) e a sua distribuição desordenada pelo território determinou a ocupação de áreas de proteção permanente (APPs), como margens de rios e encostas, tanto pelo poder público (como escolas e estabelecimentos de saúde, por exemplo), como pela população em geral. Os processos de degradação ambiental e o modelo de ocupação combinados com as características geomorfológicas e hidrometeorológicas, tornam a região vulnerável às ameaças naturais como os deslizamentos de terra e inundações. Apesar de Nova Friburgo ter um histórico de deslizamentos e enchentes recorrentes e bem conhecido pela população, as politicas de crescimento da cidade proporcionaram o aumento do risco de desastres.

A Bacia do Córrego Dantas em Nova Friburgo foi uma região extremamente atingida pelo desastre de 2011. Estudos de Coelho Netto et al. (2013) mostram que Nova Friburgo foi o município com maior intensidade de chuva (acima de 200mm em 9h) que resultou em 3.622 cicatrizes de deslizamentos em uma área de $400 \mathrm{~km}^{2}$ (COELHO NETTO ET AL., 2013). Por toda a bacia houve destruição, principalmente pelos deslizamentos translacionais rasos que promoveram barramentos temporários nos canais fluviais e transformaram-se em violentos fluxos de detritos, ocasionando grande destruição e a desconfiguração das áreas marginais aos canais, onde existiam casas, prédios e escolas. $\mathrm{O}$ desastre ocorrido e sua magnitude foi algo inconcebível para a população, assim como para os órgãos públicos que ficaram igualmente perplexos e sem condições nem preparo de atuação para responder, reabilitar e/ou reconstruir, em uma situação nunca vivida antes (11.01.2011 A EXPERIÊNCIA LIMITE, 2014).

Neste trabalho, o principal objetivo é contribuir para a construção de uma Gestão Participativa dos Riscos de Desastres na Bacia do Córrego Dantas, em Nova Friburgo, através do Sistema de Alerta e Alarme de Base Comunitária (SAABC) do bairro Cardinot. Busca-se avaliar a importância da participação dos moradores de áreas suscetíveis aos desastres nas tomadas de decisão de gestão de risco a fim de validar e incorporar em seus cotidianos às ações planejadas, contribuindo para o sucesso das mesmas.

Desta forma, os objetivos específicos do trabalho são:

1. Avaliar as estratégias e ações adotadas no Brasil para a construção de sistemas de alerta e alarme; 
2. Analisar o Sistema de Alerta e Alarme de Base Comunitária do Cardinot, como parte integrante da Gestão dos Riscos de Desastres;

3. Incentivar o fortalecimento das etapas do Sistema de Alerta e Alarme de Base Comunitária do Cardinot, conectando-o com toda Bacia Hidrográfica do córrego Dantas;

\subsection{A gestão atual dos desastre no Brasil: Por que não deu certo?}

Como panorama geral, o cenário da gestão de riscos de desastres no Brasil tem se restringido a ações governamentais militarizadas e tecnicistas, apoiadas somente no conhecimento das ciências "duras", que desconsideram a inclusão das pessoas e dos grupos socioambientalmente vulneráveis na discussão e planejamento de políticas e gestão do território. Historicamente observamos duas "forças invisíveis" perpetuando o modelo de gestão atual de desastres no Brasil. A primeira delas é a ideia de desastres como sendo um evento natural. No Brasil a classificação oficial de eventos danosos como enchentes e deslizamentos de terra, que afetam diretamente populações, é de "desastre natural". Alguns autores vêm chamando atenção para a consequência sócio-política desta visão "naturalizadora" dos desastres que, segundo Nantenzon (2002), contribuiu para uma postura de aceitação passiva da sociedade em geral, que condena o problema dos desastres a ser algo sem possibilidade de resolução, somente de monitoramento e antecipação de sua chegada, respaldando a visão tecnocêntrica do modelo de gestão. Valencio (2014) comenta:

...quando os planejadores de estado dizem que os desastres são naturais, buscam evitar um questionamento mais amplo sobre o processo sócio histórico no bojo do qual se desenrola a dinâmica sócio espacial... o domínio das ciências duras sobre o tema age como um impedimento para a adoção de uma perspectiva mais ampla de discussão...(Valencio, 2014, p. 3633 )

Esta racionalidade, segundo Quarantelli (1998), desvia o foco sobre aquilo que se processou no interior da sociedade para levarmos àquele estado de vulnerabilidade e legitima a escolha de políticas e programas que não possuem foco no bem estar e vida das pessoas, perpetuando a visão de que os desastres são eventos naturais e não socialmente construídos.

A segunda força que vem atuando e respaldando o modelo de gestão de desastres no Brasil é o de desastres como uma espécie de guerra. Trata-se de um paradigma já superado por outros países que possuem histórico de prevenção a desastres como Japão e alguns países Europeus, identificado por Gilbert (1998) em seu artigo sobre as mudanças nos conceitos que envolvem os desastres. Sobre este paradigma Valencio (2014) comenta: 


\section{OS DESAFIOS DA GEOGRAFIA FÍSICA NA FRONTEIRA DO CONHECIMENTO \\ Instituto de Geociências - Unicamp \\ Campinas - SP \\ 28 de Junho à 02 de Julho de 2017}

...nele o estado adota um discurso que exige reação diante de um agressor externo e o monitoramento constante deste "inimigo".... a deliberada confusão entre desastre e guerra favoreceu os altos investimentos em sofisticados aparatos tecnológicos, e atuação de um quadro técnico regido por uma racionalidade militarizada e com poder politico considerável...(Valencio,2014, p. 3633-3634)

Não é por acaso que quem lida com os desastres no Brasil é a Defesa Civil, reconhecida em ser uma instituição militarizada, historicamente liderada por generais, policiais ou bombeiros militares. Nota-se que neste contexto existe pouco espaço para outras áreas atuarem como as ciências sociais e as ciências da saúde, e raramente desenvolvem-se planejamentos para a gestão dos riscos de desastres em equipe interdisciplinar.

As ações de prevenção, preparação e resposta a desastres "naturais" no Brasil tem se concentrado na aquisição de aparatos tecnológicos modernos, na valorização de modelos de mensuração quantitativos de probabilidades de ocorrência de eventos perigosos e no investimento em pesquisa na área de monitoramento das condições atmosféricas, hidrológicas e climáticas, sempre dentro de uma racionalidade técnico-instrumental hegemônica. Amparado pelas ciências "duras" ou "naturais" que reduz o social ao físico e baseado na ideia de desastres como sendo naturais, os riscos também vem sendo individualizados dentro desta lógica, em um processo de "culpabilização" do indivíduo pelas condições de riscos que possam estar envolvidos. Valencio (2014) observa que existe a disseminação de uma conotação moral depreciativa dos sujeitos com comportamentos tidos como perigosos (como, por exemplo, morar em encostas de morro, em casas sem boa estrutura). Esta ideia de "culpa individualizada" faz parte de uma rede que sustenta e perpetua a racionalidade técnico-instrumental que responsabiliza grupos sociais pelas perdas e danos que sofrem frente a um evento, uma vez que considera que este é um fenômeno natural, e não um processo socioeconômico histórico de desigualdades.

...é neste processo que estão os elementos explicativos de danos e prejuízos a certas comunidades e não a outras...como também as forças que atuam na construção de um repertório discursivo que acusa certas populações de despreparadas, sem consciência, sem percepção de seu mundo... (Valencio, 2014, p. 3633)

Complexificando a problemática dos desastres no Brasil, vemos este modelo de gestão, tecnocêntrico e militarizado, atuando sobre uma sociedade cada vez mais modernizada, predominantemente urbana. Uma sociedade que introduz e normaliza os riscos cotidianamente em espaços geográficos providos de dinâmica sócio-espacial conflituosa pelo uso e ocupação da terra, com grande sobreposição cumulativa dos riscos (Beck, 1992), e que apresenta crescente dificuldade de atuação coletiva. Tudo isso vem se chocando com as limitações e incertezas dos métodos científicos tradicionais 
que não dão conta de incorporar tanta complexidade em suas análises. A visão de que a ciência não é mais a única detentora legítima do conhecimento, e que este conhecimento nunca é absoluto, mas sim permeado de incertezas (Kuhn, 2003; Leff, 2003), vem abrindo espaço entre os pesquisadores para a revalorização dos saberes locais das comunidades e isso vem se refletindo positivamente no tema desastre.

\subsection{Problemática}

Após a tragédia, nos bairros da bacia do córrego Dantas foram instaladas sirenes do sistema de alerta e alarme como parte da estratégia governamental na redução do risco de desastres na região. Trabalho de Lacerda e Coelho Netto (2014) demonstrou que há tendências negativas de comportamento da população frente ao sistema de alerta e alarme implantado, como: 1- a população reconhece estar em área de risco, mas, ao mesmo tempo, não admite que sua casa possa estar em risco; 2- a população tem conhecimento da existência das sirenes de alerta e alarme e da localização dos pontos de apoio, porém durante os eventos de chuvas em que as sirenes foram acionadas permaneceram dentro de casa; 3- a população não confia na estrutura dos pontos de apoio para abrigá-los em caso de emergência e não acredita que a existência de um plano de evacuação acionado por sirenes impossibilitará as perdas e danos tal como ocorreu em janeiro de 2011. Segundo a pesquisa, este comportamento pode ser interpretado como uma resposta à forma como o sistema de alerta foi efetivado dentro do bairro. A associação de moradores do bairro, bastante organizada, não foi devidamente inserida na discussão do sistema de alerta e alarme ou na escolha da localização dos pontos de apoio, por exemplo.

\subsection{Procedimentos}

Estudo exploratório iniciou-se no bairro do Córrego Dantas com o estabelecimento de relação com os atores-chave das comunidades do bairro, através dos encontros e reuniões promovidos na associação de moradores pela Rede de Gestão de Desastres do Córrego Dantas (REGER), rede local na qual tanto a comunidade de pesquisadores quanto a comunidade local participam. Nos intervalos destes encontros, foram mantidas conversas informais com as lideranças que manifestavam tanto insatisfações como também sugestões em relação ao sistema de alerta e alarme implantado, sendo possível correlacionar as falas com os resultados do estudo de Lacerda e Coelho Netto (2014), que afirma que o modelo das sirenes é insuficiente para gerar na comunidade uma mobilização das pessoas a saírem de suas casas durante o acionamento das sirenes. Outro fato importante que norteou a pesquisa foi o conhecimento da existência de um sistema local próprio de alerta e alarme dentro da comunidade do bairro Cardinot, que também se conectava com moradores do bairro Córrego Dantas, pertencente à mesma bacia hidrográfica. A partir destas informações foi iniciada a presente pesquisa. 
Como categoria de análise mais adequada à compreensão do Sistema de Alerta e Alarme de Base Comunitária do Cardinot, e dos elementos que contribuíram para seu desenvolvimento na localidade foi escolhida a de território. A categoria território além de abranger as características físicas e ambientais do bairro, permite também compreender o espaço historicamente construído em suas dimensões sociais, culturais, políticas e econômicas, assim como as relações de poder existentes que contribuem para um melhor entendimento da dinâmica local hoje. O conceito de território abordado nesta pesquisa considera que o território é constantemente transformado ao longo do tempo e vai ganhando forma e organização muito específicas, representando um retrato atual dos vários processos construídos ao longo do tempo e das interações entre fixos e fluxos que compõem sua estrutura. O estudo do território nos possibilita compreender e identificar quais fatores, processos e interações presentes e específicos que contribuíram para que a comunidade desenvolvesse seu próprio sistema de alerta e alarme no Cardinot.

A seleção da comunidade do Cardinot se deu principalmente pela constatação de haver no local um sistema embrionário de alerta e alarme construído ao longo de duas gerações por algumas lideranças locais. Da mesma forma a comunidade esta localizada geograficamente em local estratégico, sendo o alto curso da bacia hidrográfica do córrego Dantas, uma das bacias mais atingidas pela tragédia de 2011. A bacia do córrego Dantas vem sendo alvo de muitos estudos e pesquisa na área de desastres, em sua maioria na área de geografia e outras ciências do solo (FRAGA ET AL. 2015; SILVA ET AL., 2016), o que trás benefícios à pesquisa pela disponibilização de dados relevantes. Além disso, o bairro Córrego Dantas possui uma associação de moradores atuante e forte, aliada a Rede de Gestão de Riscos de Desastres (REGER) que catalisa ações e fomenta discussões na área de gestão de desastres e contribui diretamente no fortalecimento deste sistema de alerta em estudo.

Como procedimento teórico metodológico, foi escolhido a pesquisa-ação como sendo a abordagem qualitativa que mais se encaixou na proposta deste trabalho, uma vez que permite interagir profundamente com a comunidade de forma tanto a conhecê-la para compreender e analisar o objeto de estudo, quanto de atuar no sentido de fortalecê-la no que for necessário e estiver ao alcance dos pesquisadores como entes sociais. A pesquisa-ação nos possibilita fazer "intervenções" na comunidade, de forma colaborativa onde sujeitos e pesquisadores são atores, uma vez que representam diferentes saberes que se complementam no processo de construção da gestão participativa dos riscos de desastres (Tripp, 2005).

Optamos pela triangulação de métodos para um desenho metodológico que integrasse as várias perspectivas presentes no território, integrando abordagem qualitativa e quantitativa, com associação de múltiplos recursos para coleta de dados. Neste desenho metodológico a ênfase encontra-se na 
possibilidade de compreensão do problema investigado, o SAABC, abrindo caminhos para o diálogo entre aspectos objetivos e subjetivos do problema de pesquisa. Dentre os princípios da triangulação, esta a noção de que as narrativas e ações sociais situam-se em um local e num certo momento histórico na qual se expressam (Adorno e Castro, 1994), e desta forma é necessário ir ate este local com diferentes ferramentas que busquem captar as diferentes dimensões envolvidas. Desta forma, busca-se a construção histórica do território e suas características atuais para compreender e fortalecer o sistema local de alerta e alarme de forma horizontal e participativa na comunidade. A opção pelos instrumentos de coleta dos dados mais adequados para o objeto em estudo levou em conta a possiblidade de operacionalizar os objetivos específicos que se pretendia atingir. Para tanto, escolhemos as seguintes técnicas: pesquisa documental; pesquisa bibliográfica; entrevistas semiestruturadas; reuniões com a comunidade e observações de campo.

\subsection{Resultados}

Após a tragédia, a defesa civil iniciou uma serie de estratégias e ações para prevenção de desastres ao longo da bacia do córrego Dantas, contudo a maioria delas não teve continuidade e não funciona mais atualmente. É o caso do projeto UPC (Unidade de Proteção Comunitária) do governo do Estado do Rio de Janeiro, que além de instalar bases em containers nos bairros com riscos de desastres, contratava e capacitava agentes locais para as ações de proteção e defesa civil. Outra estratégia encerrada foi a de comunicação por celulares, que haviam sido distribuídos e mantidos pelo governo do Estado do Rio de Janeiro, com as principais lideranças dos bairros da bacia para se comunicarem gratuitamente em caso de emergências fazendo uma parceria direta com os agentes da defesa civil no monitoramento das condições locais. Esta ultima influenciou diretamente o sistema local de comunicação, que servia de informação extra para a confirmação do acionamento ou não das sirenes, assim como para estimular as trocas de informações entre as lideranças comunitárias de diferentes bairros. Sem esta rede de comunicação entre comunidade e Defesa Civil, o acionamento das sirenes passou a contar exclusivamente com os recursos tecnológicos de monitoramento de chuvas e nível dos rios, feito pelo Centro Nacional de Monitoramento e Alertas de Desastres Naturais (CEMADEN) e Instituto Estadual do Ambiente (INEA).

O acionamento das sirenes obedece a seguinte logística de ação: a Defesa Civil municipal coleta informações sobre os acumulados de chuva e o nível dos rios através da rede de monitoramento do CEMADEN e INEA, comparando-os com os estipulados nos protocolos de acionamento do sistema de alerta e alarme da Defesa Civil estadual. De forma paralela, estes órgãos também enviam alertas, que são repassados a outros órgãos antes de chegar à Defesa Civil municipal, que tem a responsabilidade de acionar o sistema. Desta forma, a desativação dos celulares das lideranças comunitárias assim como a 
interrupção do projeto das UPCs foram dificultadores para o gestor municipal ter uma base mais real das condições climáticas locais na tomada de decisão de acionar ou não as sirenes, assim como para organizar a logística de abertura dos pontos de apoio e acolhimento dos moradores.

Atualmente o Sistema de Alerta e Alarme do bairro Cardinot serve para reduzir o risco de inundações. As pessoas envolvidas no sistema percebem a ameaça através da intensidade e duração da chuva e através do monitoramento visual do nível do córrego Dantas e a divulgação do alerta é feita bocaa-boca. A população, uma vez alertada, inicia procedimentos de resguardo de seus pertences e evacuação das casas. Por exemplo, ao observar a altura do rio próximo a sua casa, o Sr. Juca Cardinot, liderança local, se comunica com seu sobrinho Sr. Gustavo Cardinot e vice versa, que mora na parte alta do bairro, perto da nascente do córrego Dantas. Dependendo da situação encontrada, o Sr. Juca se comunica com o Sr. Édmo, morador do bairro Córrego Dantas, e este por sua vez avisa as outras lideranças do bairro e de bairros vizinhos que residem a jusante. Foi graças a este sistema simples de comunicação comunitária interna, que 28 pessoas foram salvas no Cardinot no dia da catástrofe, onde o Sr Juca, tendo se comunicado com seu sobrinho na parte alta do bairro, teve tempo para retirar de suas casas os moradores da parte baixa, que não faziam ideia da magnitude das chuvas que estavam ocorrendo. Os moradores desalojados foram levados para a igreja, utilizada como um abrigo, tendo a agua subido 3 metros de altura minutos depois, inundando completamente todas as casas daquela localidade. Vale apontar que após a tragédia de 2011 a Defesa Civil municipal havia instituído como ponto de apoio a escola municipal do bairro, que segundo os moradores no dia da tragédia ficou imersa em 2 metros de altura, o que demonstra um claro episódio de falta de diálogo com a população local.

Ao perguntarmos o que precisaria ser feito para fortalecer e melhorar o sistema de alerta e alarme local, a resposta unânime sobre a necessidade de instalar um sistema de comunicação estável e que funcione mesmo nas condições atmosféricas mais severas e que não dependa do fornecimento de energia elétrica pela concessionária e de sinal de celular. Os próprios moradores indicaram um sistema de comunicação via rádio. Com esta informação chave, foi articulado com membros da REGER a aquisição destes equipamentos. Uma das instituições parceiras da Rede, o Centro de Estudos e Pesquisa em Emergências e Desastres em Saúde (CEPEDES) da Fundação Oswaldo Cruz (Fiocruz), disponibilizou um recurso adquirido, doado pela empresa Deloitte, o que possibilitou a compra de equipamentos de radiocomunicação com o objetivo de apoiar as ações durante emergências e auxiliar nos processos de mobilização das comunidades dos bairros da Bacia do Córrego Dantas. Paralelamente a aquisição dos equipamentos pela REGER, foi iniciada nas comunidades da bacia uma divulgação e fomento da ideia de um curso de radio amador entre os moradores com perfil e vontade para assumir esta função na comunidade. Após a realização de um intenso trabalho de mobilização das diferentes comunidades da 
bacia do Córrego Dantas por membros da REGER, foi realizado encontro para formação da Rede de Comunicações da Bacia do Córrego Dantas, com a participação de moradores dos bairros distribuídos pela bacia do córrego Dantas. Neste momento esta rede era formada por 17 pessoas distribuídas em um total de 13 residências (Figura 1) e praticamente todos os seus integrantes foram instrumentalizados com rádios através de um curso de capacitação para radio amador sediado na associação de moradores local. Esta se configurou na primeira importante ação de fortalecimento do SAABC em construção no bairro do Cardinot, fruto da parceria entre pesquisadores, comunidade e associação de moradores com as instituições parceiras da REGER, que reforça o aprendizado coletivo para uma gestão participativa dos riscos de desastres.

Foi realizado o mapeamento dos riscos relacionados a desastres na comunidade do Cardinot, que tiveram inicio através de convite à comunidade a participar das ações e encontros relacionados à pesquisa. Utilizando a ferramenta Google Earth, projetado na parede com a utilização do projetor de dados (datashow) foram mapeados de forma participativa, os riscos e potencialidades locais para desastres cujas informações foram marcadas no mapa projetado para observação de todos (figura 2). Foi mapeado 1- as moradias dos que estavam presentes e as áreas de risco de enchentes e deslizamentos, especificando o nível de risco (alto e baixo) atribuído segundo a percepção dos participantes; 2- a moradia dos grupos vulneráveis, especificando o tipo de vulnerabilidade existente o local, sendo crianças de 0-14, gestantes, idosos e portadores de algum tipo de deficiência; 3- os possíveis pontos de apoio em caso de emergência, vias de acesso e rotas de fuga; 4- os recursos materiais que poderiam ser uteis em caso de emergência como tratores, motosserras, carros com tração, rádios; e 5- os recursos humanos da comunidade como trabalhadores da área de saúde (enfermeiras, médicos, paramédicos, agentes de saúde), bombeiros, agentes de defesa civil, servidores públicos do município e tudo mais que a comunidade julgou ser potencialmente benéfico para situações de emergência.

Em um segundo momento, foi realizado levantamento das iniciativas de monitoramento já existentes no bairro (figura 3). Perguntas como: quais pessoas já possuem o costume de monitorar o rio e quais de monitorar a chuva, além de levantar como fazem isso, foram feitas. Como resultado foram mapeados cinco moradores que já vem monitorando a chuva através da subida da agua nos rios e um morador indicou já realizar o monitoramento da quantidade de chuvas através de pluviômetro caseiro. Também foi identificado com a comunidade e marcado no mapa os principais locais que segundo eles seriam locais estratégicos para o monitoramento dos rios, como pontes e encontros de rios.

\subsection{Considerações finais}




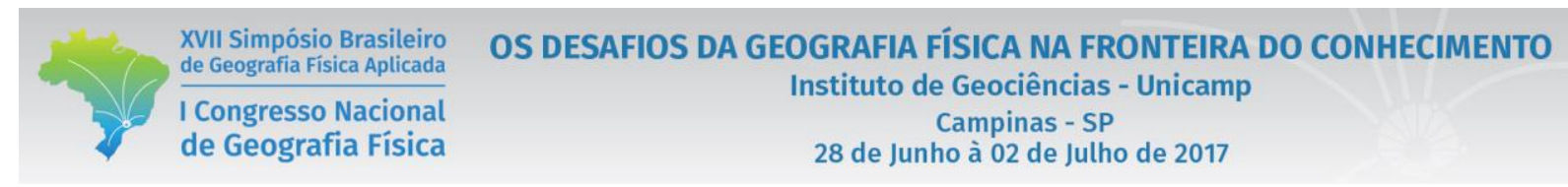

Atualmente o sistema de alerta e alarme de base comunitária do Cardinot possui pouca abrangência na bacia hidrográfica assim como poucas pessoas envolvidas para propagar a informação para um grande número de moradores de áreas de risco, sendo necessário sensibilizar e motivar a comunidade neste sentido. O sistema demostra que a comunidade possui seus próprios meios de gestão de riscos, mas que estes sozinhos são limitados, precisando de apoio externo, o que é diferente de impor estratégias e ações pensadas de "fora" da realidade local. Mais do que ouvir as comunidades susceptíveis, é necessário incorporar os saberes da comunidade no planejamento de ações de prevenção a desastres.

A implantação de radiocomunicação nos bairros da bacia hidrográfica é um grande avanço na comunicação e disseminação de informações em situações de emergência e trás segurança nas lideranças comunitárias locais. No entanto a gestão de riscos de desastres ainda é realizada pela comunidade sem o apoio governamental, que permanece com o modelo de gestão tecnocêntrico e militarizado.

Sem espaço para o conhecimento de planejadores urbanos, geógrafos, psicólogos, assistentes sociais, historiadores, sociólogos dentre outros saberes importantes na área de desastres, restringimos e limitamos a gestão dos riscos de desastres a estratégias baseadas na experiência de guerra e nas tecnologias de monitoramento e antecipação dos eventos, importantes, mas não suficientes. Desta forma se torna muito difícil aumentar a resiliência de comunidades susceptíveis e reduzir as vulnerabilidades das mesmas, preparando-as para minimizar ou anular os impactos dos eventos naturais. Politicas de gestão de riscos de desastres devem ser discutidas abertamente com toda sociedade civil interessada para que as ações se sustentem, sejam eficientes e evitem futuros conflitos territoriais.

\section{Figuras e Tabelas}

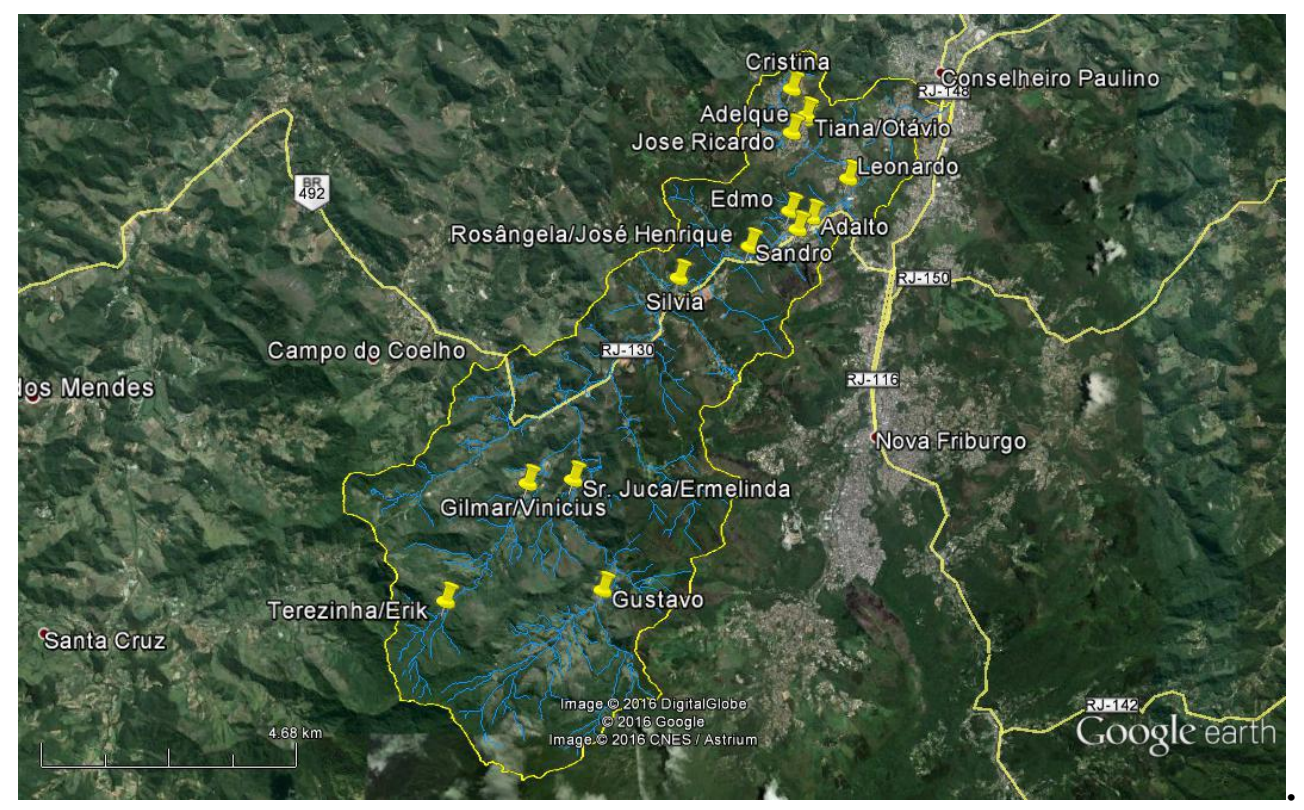


XVII Simpósio Brasileiro de Geografia Fisica Apli

I Congresso Nacional de Geografia Física
OS DESAFIOS DA GEOGRAFIA FÍSICA NA FRONTEIRA DO CONHECIMENTO

Instituto de Geociências - Unicamp

Campinas - SP

28 de Junho à 02 de Julho de 2017

Figura 1: Rede de Radiocomunicação do Sistema de Alerta e Alarme de Base Comunitária da Bacia do Córrego Dantas.

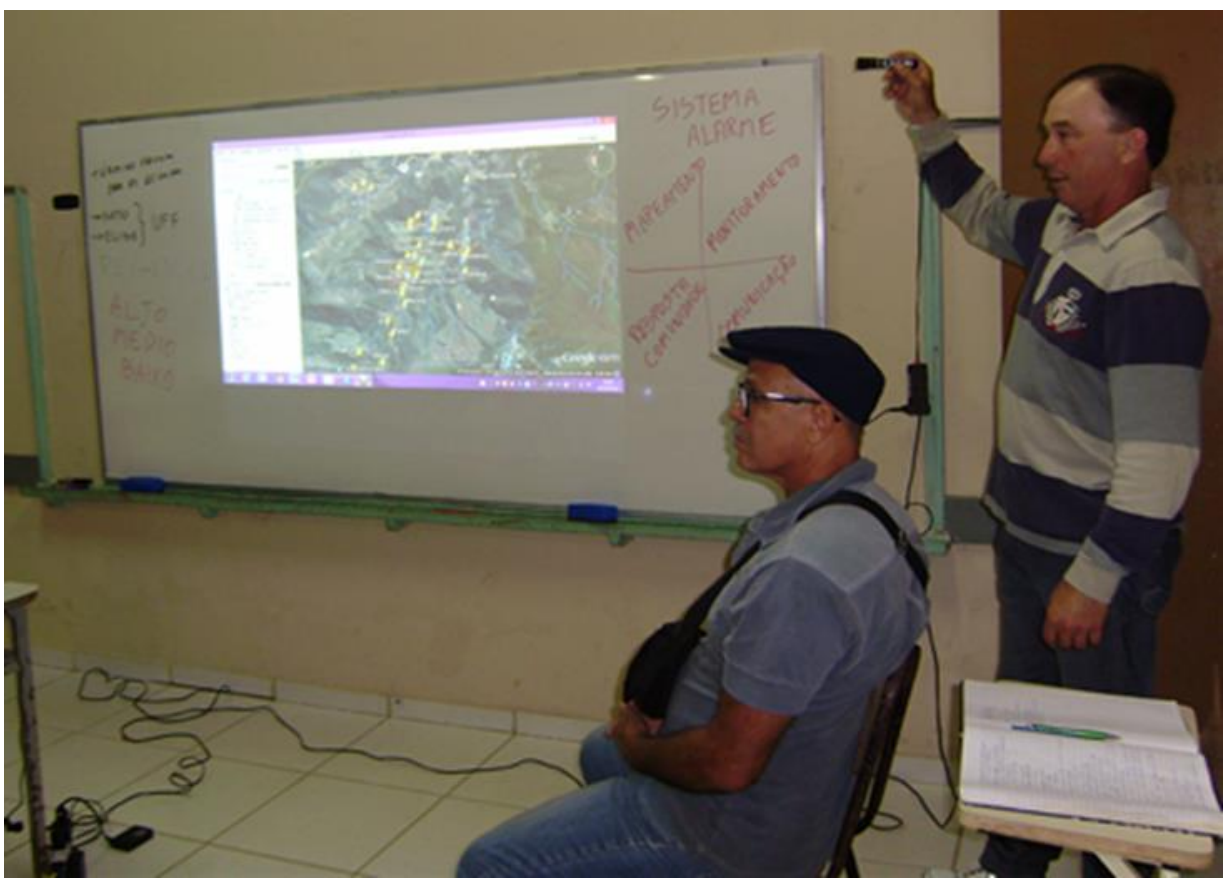

Figura 2: Reuniões na comunidade: Levantamento e mapeamento participativo dos riscos e potencialidades para desastres do Cardinot.

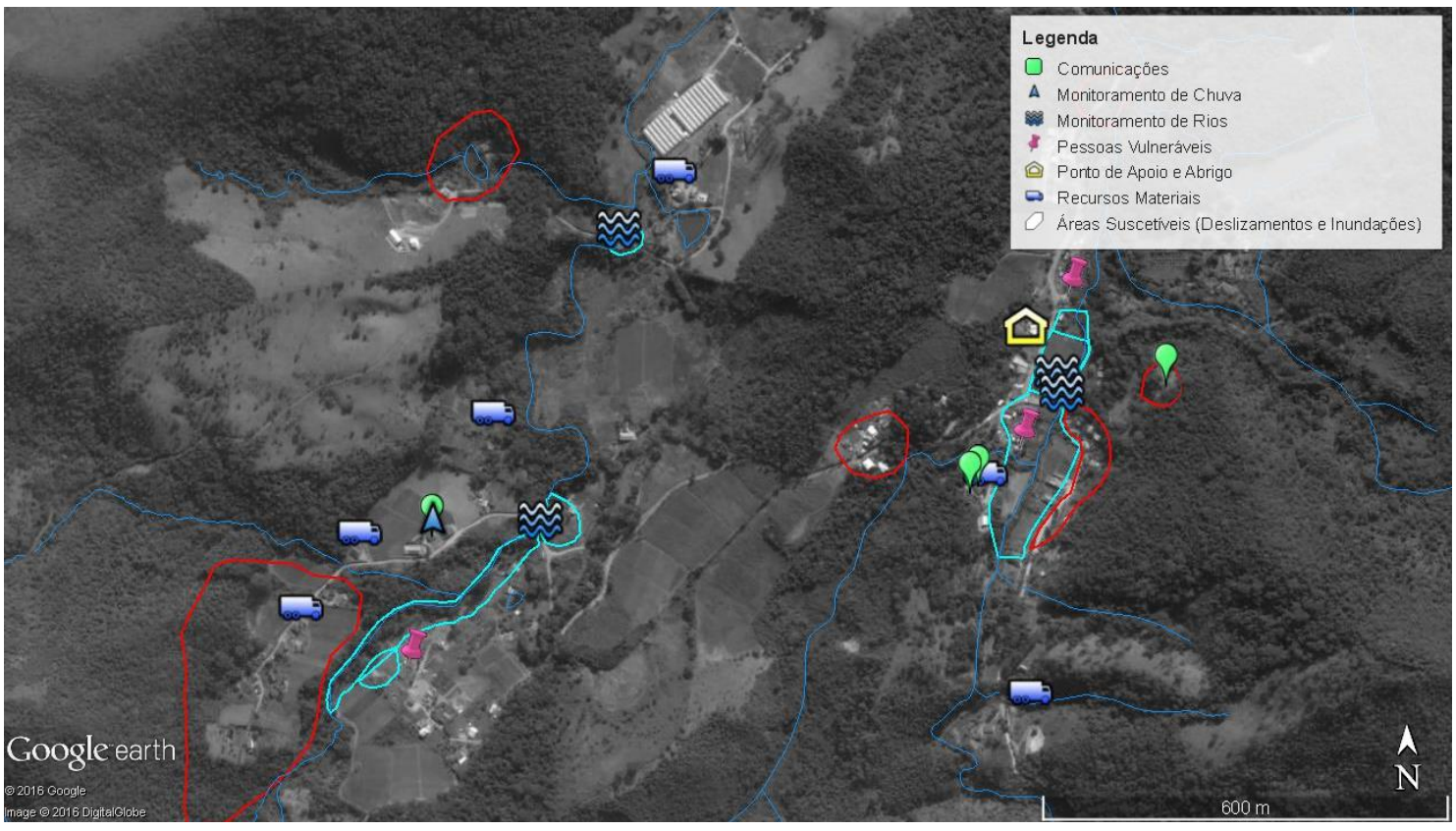

Figura 3: Mapa elaborado com a participação de moradores, técnicos e pesquisadores. Fonte: autoria própria da pesquisa 


\section{Bibliografia}

ADORNO, R. C. F.; CASTRO, A. O exercício da sensibilidade: pesquisa qualitativa e a saúde como qualidade. Saúde soc., vol.3, n.2, pp. 172-185. 1994.

BANCO MUNDIAL. Avaliação de Perdas e Danos: Inundações e Deslizamentos na Região Serrana do Rio de Janeiro - Janeiro de 2011. Banco Mundial: Brasília, p. 59. 2012.

BECK U. Risk society: towards a new modernity. New Delhi, Sage, 1992.

BERTONE, P.; MARINHO, C. Gestão de riscos e resposta a desastres naturais: a visão do planejamento. Anais do VI Congresso CONSAD de Gestão Pública, Brasília, p. 27. 2013.

TRIPP, D. Pesquisa-ação: uma introdução metodológica. Educação e Pesquisa, São Paulo, v. 31, n. 3, p. 443-466, set./dez. 2005.

FRAGA, J. S., NETTO, A. M. C., SATO, A. M. Comparação da condutividade hidráulica na zona de raízes entre dois fragmentos de florestas secundárias de montanha em Nova Friburgo/RJ. Revista Geonorte, v.5(14), p. 48-53, 2015 .

FREITAS, L. E.; NETTO, A. M. C. Reger córrego Dantas: uma ação coletiva para enfrentamento de ameaças naturais e redução de desastres socio-ambientais. Ci. \& Tróp. Recife, v. 40, n. 1, p. 165-190, 2016.

GILBERT C. Studying disaster: changes in the main conceptual tools. In: Quarantelli E, editor. What is a disaster? Perspectives on the question. London, New York: Routledge, 1998, p.11-18.

KUHN T. S. A estrutura das revoluções cientificas. $7^{\text {a }}$ ed. São Paulo: Perspectiva; 2003.

LEFF H. Pensar a complexidade ambiental. In: Leef H, Organizador. A complexidade Ambiental. São Paulo: Cortez, 2003, p. 15-64.

NATENZON C. Vulnerabilidad, Incertitumbre y Planificación Participativa de Desastre: el caso de las inundaciones catastróficas em Argentina. In: Porto MSF, Freitas CM, Organizadores. Problemas Ambientais e Vulnerabilidades, abordagens integradoras para o campo da Saúde Pública. Rio de Janeiro: CESTEH/ENSP/FIOCRUZ, 2002, p. 5778.

NETTO, A. L. C.; SATO, A. M.; FREITAS, L. E. Land Use-Vegetation-Landslide Interactions in the Mountainous Region of Rio de Janeiro State: Scientific Basis for Risk Assessment and Management. Anais Regional Conference of International Geographical Union, Moscow, 2015.

NETTO, A. L. C.; SATO, A. M.; AVELAR, A. S.; VIANNA, L. G. G.; ARAÚJO, I. S.; FERREIRA, D. L. C.; LIMA, P. H. ; SILVA, A. P. A.; SILVA, R. P. January 2011: The Ex-treme Landslide Disaster in Brazil. In: Claudio Margottini; Paolo Canuti; Kyoji Sassa. (Org.). Landslide Science and Practice. 1ed. Berlin: Springer Berlin Heidelberg, 2013, v. 6, p. 377-384.

NETTO A. L. C.; LACERDA N. A Gestão de Áreas de Risco a Deslizamentos e Estratégias de Resposta a Desastres: um estudo sobre a percepção de risco da população local através do sistema de alerta e alarme. In: VI CONGRESSO IBEROAMERICANO DE ESTUDIOS TERRITORIALES Y AMBIENTALES. 2014. São Paulo. Disponível em: http://6cieta.org/arquivosanais/eixo4/Nathalia\%20Lacerda\%20de\%20Carvalho,\%20Ana\%20Luiza\%20Coelho\%20Netto.pdf

PORTELlA, S. L. D.; OLIVEIRA, S. S.; PLANEL, G. A Experiência Limite (Filme-vídeo). Produção e Direção de Sérgio Luís Dias Portella, Simone Santos Oliveira e Guillermo Planel. Rio de Janeiro, Escola Nacional de Saúde Pública da Fundação Oswaldo Cruz. Disponível em: <https://www.youtube.com/watch?v=7SfH7VBitbE>. Acesso em: 10 jan. 2016.

QUARANTELLI E. L. Epilogue. In: Quarantelli E.L., editor. What is a disaster? Perspectives on the question. London, New York: Routledge, 1998, p. 234-273. 


$\begin{aligned} & \text { XVII Simpósio Brasileiro } \\ & \text { de Geografia Fisica Aplicada }\end{aligned}$
$\begin{aligned} & \text { I Congresso Nacional } \\ & \text { de Geografia Física }\end{aligned}$

SILVA, R. P.; MACHADO, K. M.; SILVA JUNIOR, G. C.; COELHO NETTO, A. L.; BECKER, L. B. ; SATO, A. M. . Determinação de parâmetros físicos do solo em encosta sob influência de escorregamento translacional raso Nova Friburgo, RJ. Revista Brasileira de Geologia de Engenharia e Ambiental, v. 4, p. 51-64, 2016.

VALÊNCIO N. F. L. S. Desastres: tecnicismo e sofrimento social. Ciênc. saúde coletiva, RJ, v.19(9), p. 3632-3644, 2014. 